\title{
APPLICATION OF PERMANENT DRY HIGH INTENSITY MAGNETIC SEPARATION FOR THE PROCESSING OF SPENT FCC CATALYST
}

\author{
M.C. LEAPER ${ }^{\mathrm{a}}$, S.W. KINGMAN ${ }^{\mathrm{b}, *}$ and J.P.K. SEVILLE \\ ${ }^{a}$ Wolfson Centre for Bulk Solids Handling, University of Greenwich,

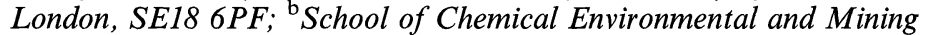 \\ Engineering, University of Nottingham, University Park, Nottingham, \\ NG7 2RD; ${ }^{\mathrm{c}}$ Department of Chemical Engineering, University of Birmingham, \\ Edgbaston, Birmingham, B15 2TT
}

(Received 10 September 2001; Accepted on 26 September 2001)

This paper discusses the application of permanent dry high intensity magnetic separation to improve the efficiency of Fluidised Catalytic Cracking (FCC) systems used in oil refining, causing preferential removal of deactivated (spent) catalyst from the process. It was shown that this technique can provide efficient separation of spent catalyst from fresh, despite some loss of fine particles. The effects of particle segregation were also investigated, with both magnetic and nonmagnetic particles. Separation was found to be particularly good for material above $90 \mu \mathrm{m}$, but efficiency decreased below this particle size. The paper concludes with recommendations for the implementation of the technology.

Keywords: Dry magnetic separation; Catalyst

\section{INTRODUCTION}

Fluidised Catalytic Cracking (FCC) is widely used in the petroleum industry to process crude oil feed prior to the main fractionating separation. It converts low-value long chain hydrocarbons present

\footnotetext{
*Corresponding author.
} 


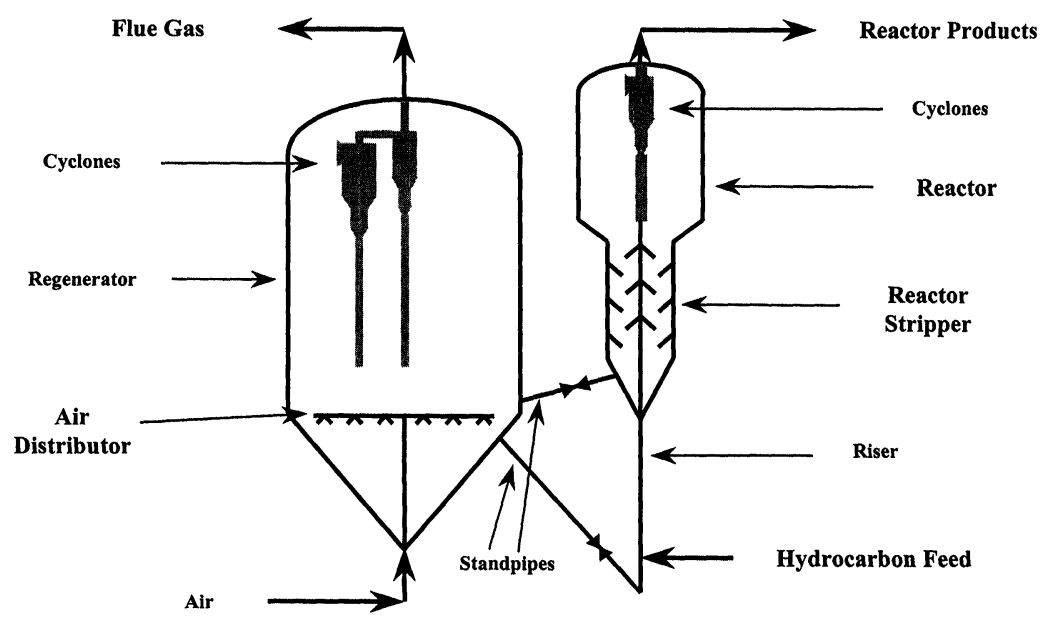

FIGURE 1 Schematic diagram of FCC system.

in crude oil to smaller molecules of higher values used for gasoline production. Figure 1 is a schematic diagram of the process. The hydrocarbon feedstock is injected into the system in a droplet/ vapour form which is then contacted with the particulate FCC catalyst in a reactor. This mixture is then transported to a riser within the reactor, within which the reaction takes place and separation of the catalyst and gaseous product occurs. The gaseous hydrocarbons exit the process to be used elsewhere in the refinery. The particles then pass through a steam stripper, where any residual gas is removed from the porous particles. During the reaction process the particles become coated with a coke bi-product (causing immediate deactivation) and have to be fluidised in oxygen-enriched air to burn this off (regeneration) before passing through the process again. This is achieved by introducing the particles to a stream of air via a standpipe, resulting in pneumatic transport to the regenerator. The regenerator operates in the fast fluidisation mode, with cyclones and diplegs present within the vessel to return elutriated particles to the bed. The resultant regenerated particles are then recycled back to the reactor stage via another standpipe. The catalyst particles themselves are typically of diameter $40-200 \mu \mathrm{m}$ and density $1200 \mathrm{~kg} \mathrm{~m}^{-3}$. 



\section{EXPERIMENTAL BACKGROUND}

For the experimental investigations three catalyst materials were used, all of which were representative of real catalyst materials extracted from operating plants. Details of each catalyst are given in Table I. Material A was fresh 'as received' catalyst, material B was E-CAT from a European plant and material $\mathrm{C}$ was E-CAT from a Far Eastern operation. Iron and nickel contents were determined by chemical analysis.

Magnetic separation tests were carried out on an Eriez Magnetics rare earth roll magnetic separator. A schematic of the design is presented in Fig. 2. During the separation, three competing forces act on each particle - magnetic, gravitational (or buoyant) and drag forces [3], and can be represented by the equations:

$$
\begin{gathered}
F_{m}=f(d, B, \kappa) \\
F_{g}=\frac{\pi d^{3}}{6}\left(\rho_{p}-\rho\right) g \\
F_{d}=f\left(R e_{p}\right)
\end{gathered}
$$

The magnetic force on a particle is a complex relationship between particle volume, a function of $d^{3}$, magnetic field strength, $B$ (the unit of magnetic field strength is the Tesla (T), $1 \mathrm{Am}^{-1}$ is equivalent to $4 \pi \times 10^{-3} \mathrm{~T}$ ), and particle magnetic susceptibility, $\kappa$. Drag force is calculated by a standard method and is a function of the particle Reynolds number $R e_{p}$ [4]. One immediate consequence of this is that as particle size decreases, drag force decreases linearly, at the low $R e_{p}$ conditions in this experiment whereas buoyancy and magnetic force decrease with a cubic characteristic. This means that the effective-

TABLE I Iron and nickel analysis of experimental feed materials

\begin{tabular}{lcc}
\hline Material & $\begin{array}{c}\text { Ni }(\mathrm{ppm}) \\
\text { Content }\end{array}$ & $\begin{array}{c}\text { Fe }(\mathrm{ppm}) \\
\text { Content }\end{array}$ \\
\hline $\mathrm{A}$ & 20 & 2500 \\
$\mathrm{~B}$ & 3000 & 9500 \\
$\mathrm{C}$ & 2500 & 5500 \\
\hline
\end{tabular}




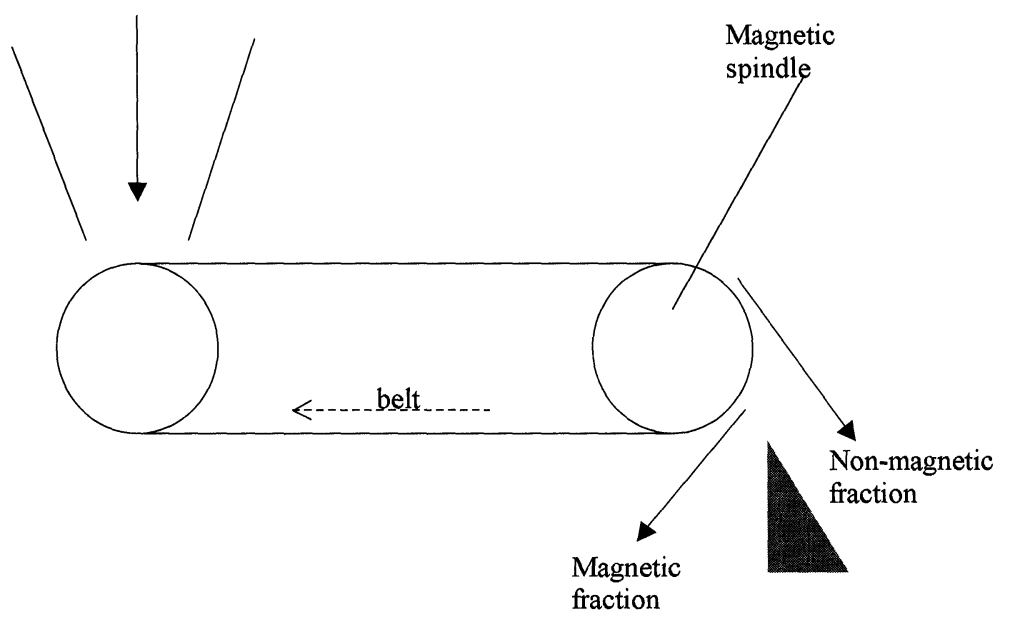

FIGURE 2 Schematic of Eriez laboratory scale rare earth roll separator.

ness of magnetic separation decreases with the particle size of the system, as drag force differences become the dominant factor.

\section{EXPERIMENTAL METHOD}

Before each set of experiments, preliminary tests were carried out to ensure that the belt speed, vibratory feeder setting and blade position give the most efficient separation. This task was made easier by the fact that the split was found to be very clear. The belt speed was kept at a constant $0.6 \mathrm{~m} / \mathrm{s}$, this was done to stop excessive carry over of magnetic material into the nonmagnetic fraction. The test material was passed through the system, representative samples of each fraction being taken for analysis. This was done using a spinning riffle. The nonmagnetic fraction was passed through the system again, being repeated until five samples of magnetic fraction and five samples of nonmagnetic fraction were obtained. Size analysis was carried out by a laser scattering technique using a Malvern Mastersizer. Approximately $3-5 \%$ of the initial mass was lost through displaced air carrying away the fines onto remote surfaces of the equipment. The starting material was $1 \mathrm{~kg}$ of a $50 / 50$ mixture of fresh (A) and 
E-cat; experiments were performed for both types (B) and (C) E-cats. The samples were analysed for particle size distribution, nickel content and iron content.

This test procedure was then repeated using only A on its own and then various size fractions of $\mathrm{B}$ and various size fractions of $\mathrm{C}$. This was carried out to investigate the effect of size distribution on the process.

\section{RESULTS AND DISCUSSION}

Figure 3 shows how a mixture of fresh catalyst and E-cat can be separated by comparing the cumulative percentage of the total nickel content of the mixture ( $y$-axis) with the cumulative mass passed through the system ( $x$-axis). A $45^{\circ}$ line indicates that there is no selectivity. It can be seen that for the $\mathrm{A} / \mathrm{B}$ mixture the spent catalyst separates more efficiently than the $\mathrm{A} / \mathrm{C}$ mixtures with $5 \%$ more of the

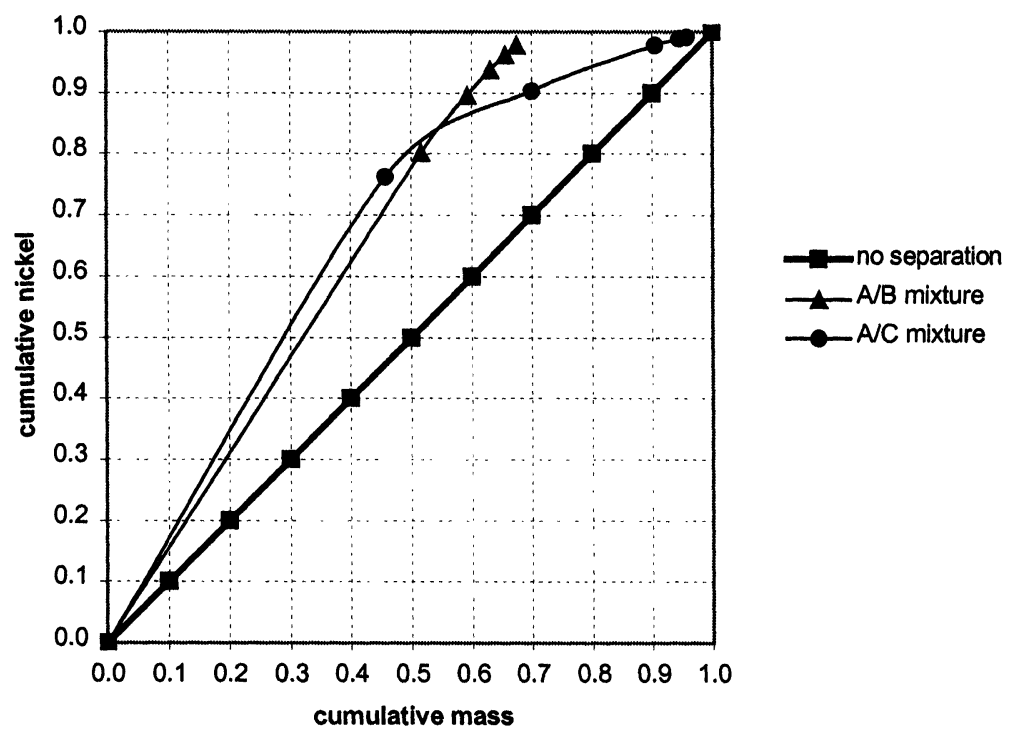

FIGURE 3 Measuring catalyst nickel content to evaluate separation of E-cat/fresh mixtures. 


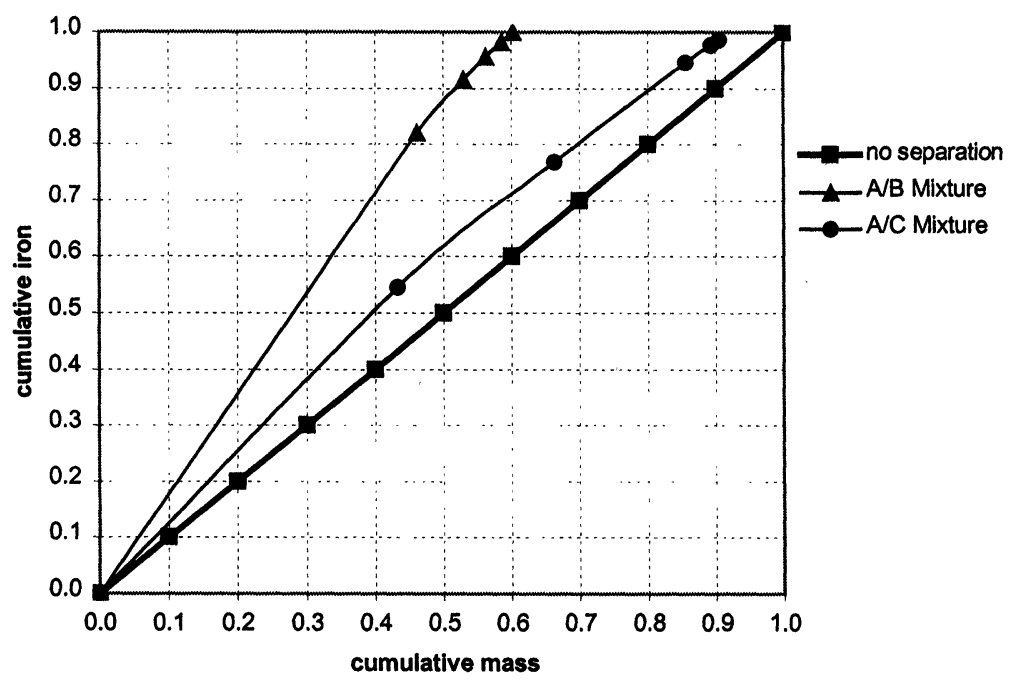

FIGURE 4 Measuring catalyst iron content to evaluate separation of E-cat/fresh mixtures.

total nickel in the system recovered after the first pass. The probable reason for the improved separation efficiency is a higher magnetic susceptibility due to increased iron content. Figure 4 shows the cumulative mass of sample versus the cumulative recovery of iron. These plots different slightly from those in Fig. 3 in that they are more linear. This is particularly true for the recovery of spent catalyst from the $\mathrm{A} / \mathrm{C}$ mixture, where for the first stage $42 \%$ of the total mass was recovered corresponding to $55 \%$ cumulative iron. For the second pass $67 \%$ of the mass gave a cumulative iron recovery of $78 \%$. This means that the iron in the $\mathrm{A} / \mathrm{C}$ mixture is more difficult to separate than that in the A/B mixture this was probably related to the fact that $\mathrm{B}$ had a very high iron content. It also indicates that an $\mathrm{A} / \mathrm{C}$ mixture may be difficult to separate on an industrial scale due to the number of passes required to give a satisfactory cumulative recovery.

Another objective of this study was to investigate the extent of the migration of nonmagnetic (fresh) particles to the magnetic (spent) stream. Figure 5 shows the particle size distribution of the exit streams when a sample of fresh catalyst of mass $1 \mathrm{~kg}$ is split $50 / 50$ by mass using the belt separator. The stream that was 'flung' furthest from the belt 


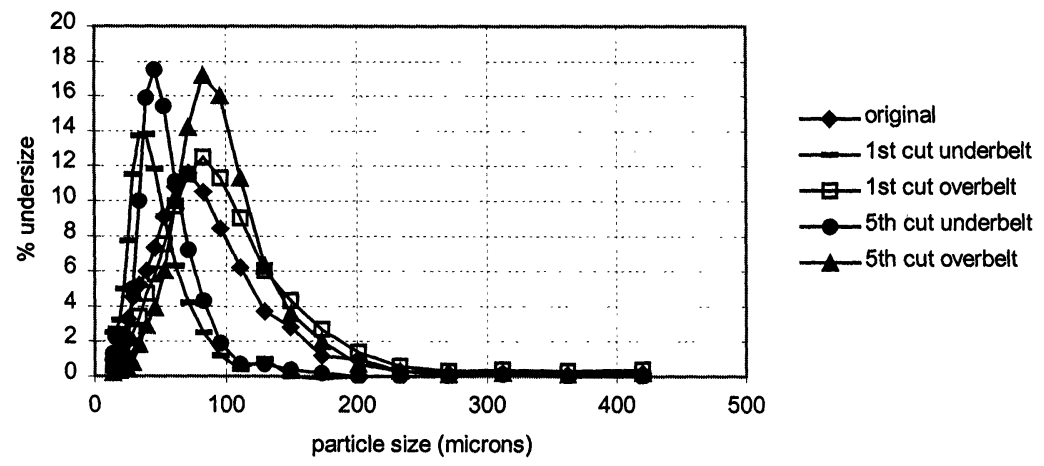

FIGURE 5 Plot of cumulative \% undersize for A catalyst passed over roll separator.

(the "overbelt") is passed over again five times. In the first pass, the stream that passes under the magnetic spindle (the "underbelt") is richer in fines as expected, but this effect continues even after the fifth pass.

With each pass the starting particle size distribution gradually becomes coarser, pushing the associated curves to the right. As discussed in the experimental background, this can be explained by the fact that under the experimental conditions, drag forces become more dominant as particle size decreases, reducing linearly as opposed to a cubic relationship for gravitational and magnetic force.

The carry over of nonmagnetic material into the magnetic fraction could also be related to electrostatic attractive forces between the belt and the particles, although attempts were made to stop this by use of Kevlar belt. The carry over of material is certainly not advantageous in the magnetic separation of this type of material. Due to the required inventory and costs of fresh catalyst it is important that as much unspent material reports to the nonmagnetics as possible.

The next stage of the work was to examine how particle size distribution changes during magnetic separation and the effect this has on separation efficiency. The particle size distributions were measured for the fresh/E-cat mixture to determine whether all the fines went into the magnetic stream at the beginning or if it was a gradual process. Figure 6 shows that the initial magnetic cut is considerably richer in fines, caused by segregation. After five passes all cuts were considerably coarser than the initial mixture. 


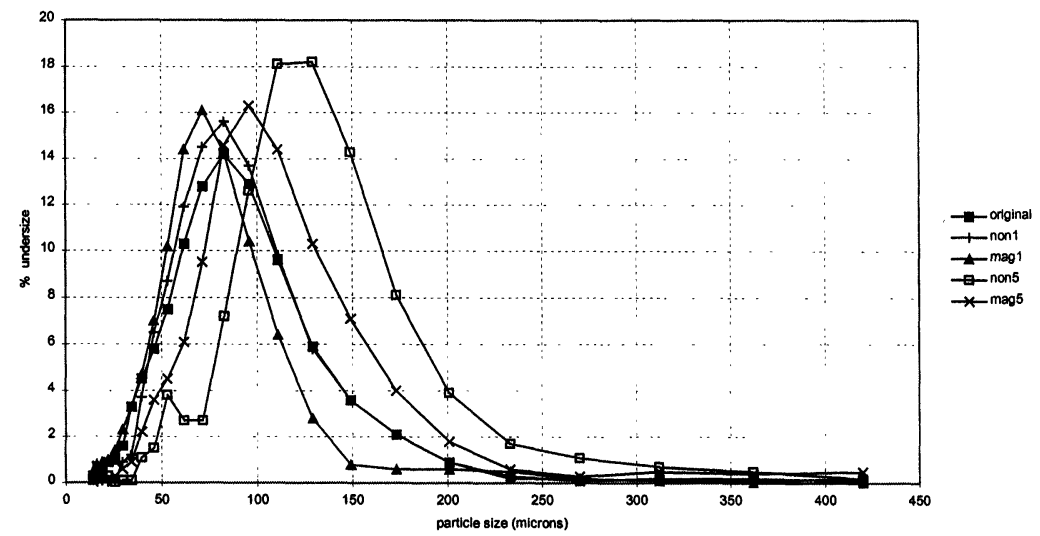

FIGURE 6 PSD of both magnetic and nonmagnetic cuts with successive passes through the magnetic separator $(\mathrm{C} /$ fresh mixture) .

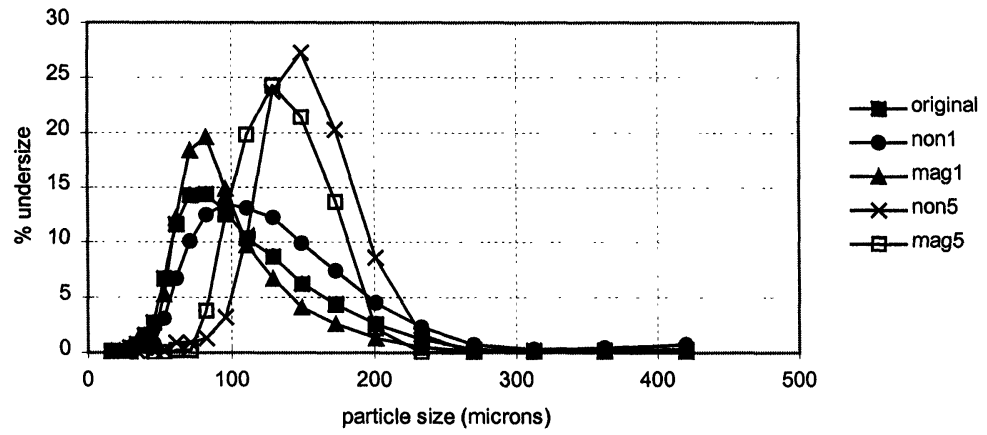

FIGURE 7 PSD of both magnetic and nonmagnetic cuts with successive passes through the magnetic separator (C normal size distribution).

Figure 7 shows how $\mathrm{C}$ catalyst alone separates. The initial magnetic fraction has a similar size distribution to the fresh/E-cat mixture with a similar coarser size distribution after five passes, again showing that fines are removed relatively quickly. Figures 8 and 9 show the effects of controlling the size distribution through sieving. It is noticeable that the curves converge when the operating size distribution is narrowed. Figures 10 and 11 illustrate the effect of changing the 


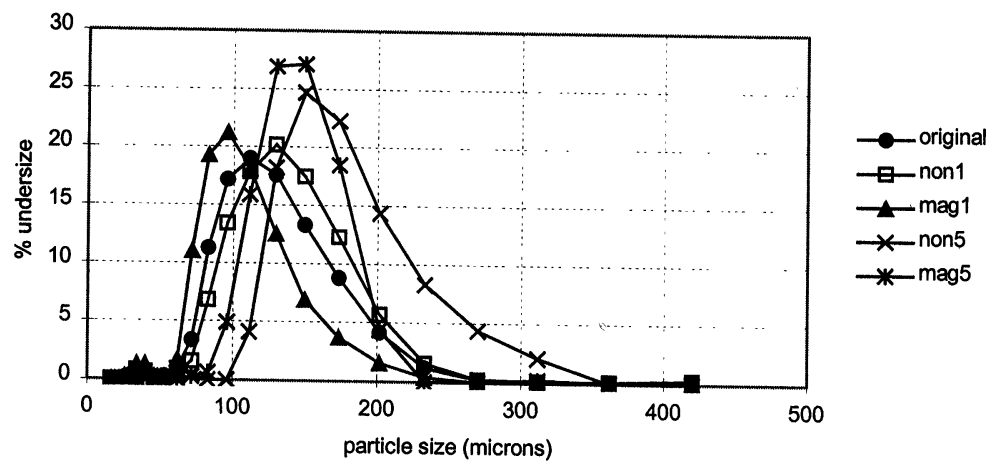

FIGURE 8 PSD of both magnetic and nonmagnetic cuts with successive passes through the magnetic separator $(\mathrm{C} 90 \mu \mathrm{m}+)$.

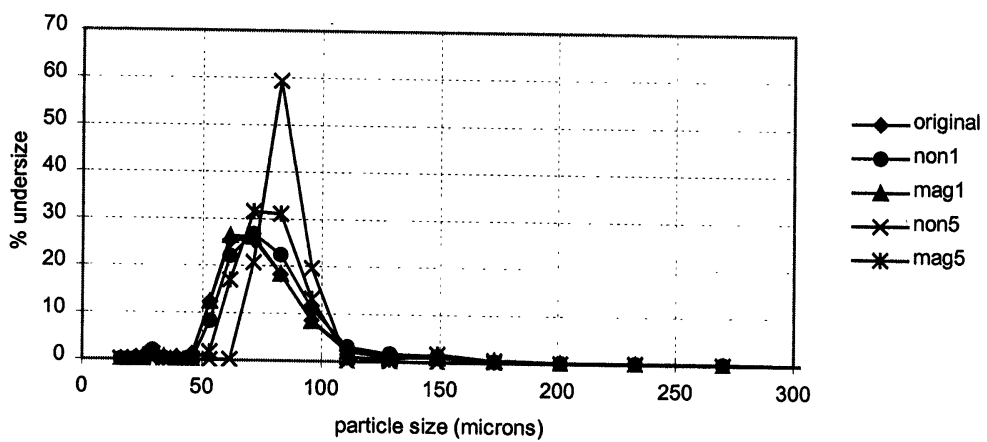

FIGURE 9 PSD of both magnetic and nonmagnetic cuts with successive passes through the magnetic separator $(\mathrm{C} 75-90 \mu \mathrm{m})$.

size distribution on the efficiency of separation with respect to nickel content. It can be seen that the separation efficiency is much greater for larger material the best separation occurring for the $-90 \mu \mathrm{m}$ material. This was true for both C catalyst in Fig. 10 and B catalyst in Fig. 11. This is not a surprising result, as the limit of separation for the type of separator employed is approximately $50 \mu \mathrm{m}$. The reason for this limit of separation is the balance between drag forces and magnetic forces. Below $50 \mu \mathrm{m}$ drag forces dominate magnetic forces and separation based on magnetic properties alone is not possible. 


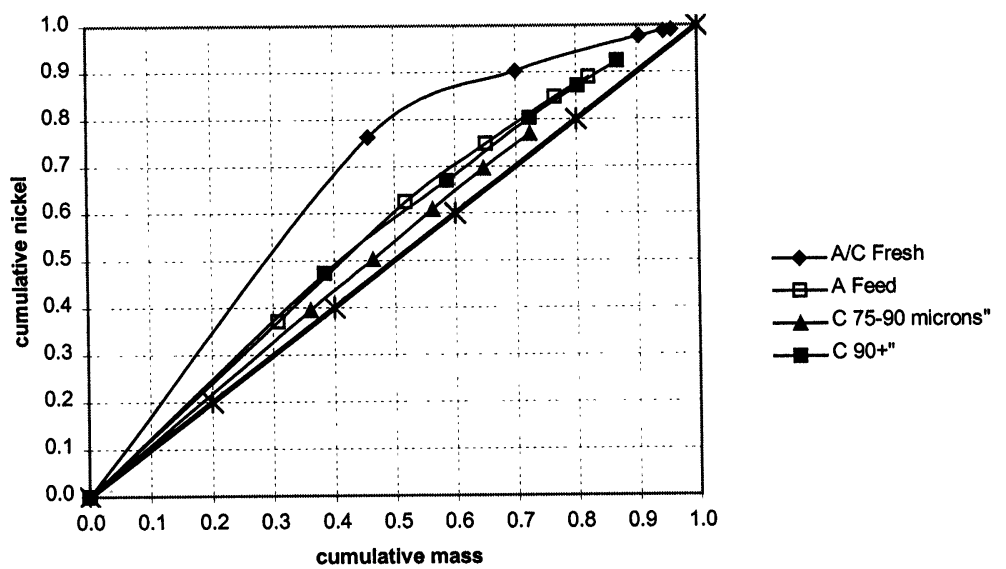

FIGURE 10 Comparing separation efficiencies for $\mathrm{C}$ catalyst of different size distributions (with respect to nickel content).

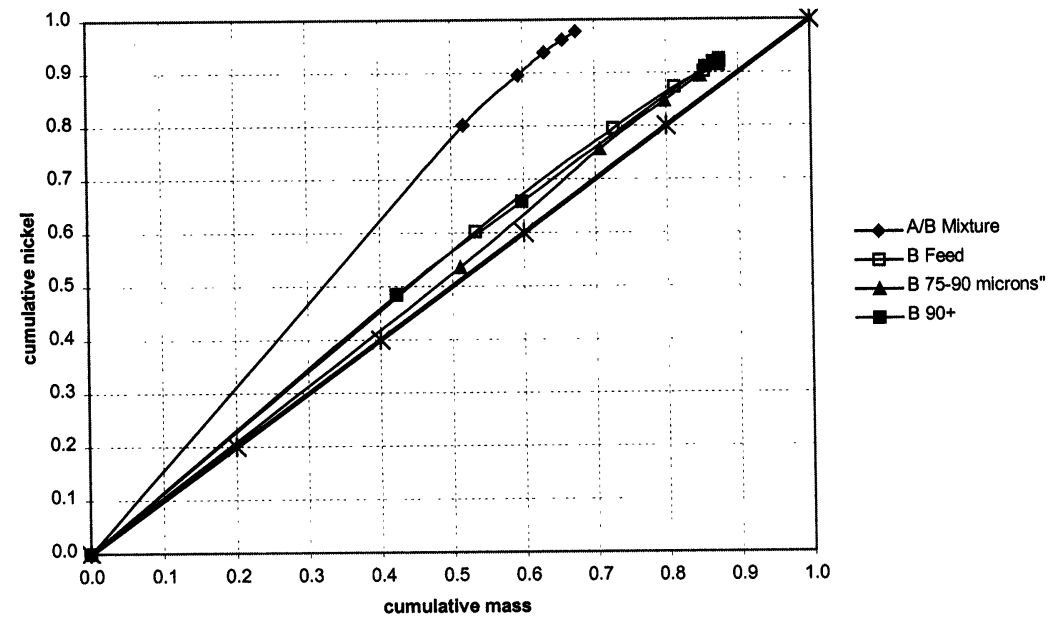

FIGURE 11 Comparing separation efficiencies for B catalyst of different size distributions (with respect to nickel content).

\section{CONCLUSIONS}

This paper has shown that it is possible to separate fresh catalyst from spent catalyst, although losses of fine fresh catalyst are signifi- 
cant, possibly due to drag effects. It is also possible to significantly reduce the nickel content of E-cat by this method, although similar issues exist with fines. If size distribution is narrowed, the segregation effect is reduced, although with finer particles separation becomes more difficult as drag forces dominate the difference in magnetic forces. It is concluded therefore that this technique may be suitable for separating E-cat flows with 'normal' size distributions but applicability may be reduced if the size distribution is predominantly below $90 \mu \mathrm{m}$.

\section{NOMENCLATURE}

\begin{tabular}{|c|c|}
\hline$F_{m}$ & Magnetic force $\mathrm{N} \quad \mathrm{MLT}^{-2}$ \\
\hline$F_{g}$ & Gravitational force $\mathrm{N} \mathrm{MLT}^{-2}$ \\
\hline$F_{d}$ & Drag force $\mathrm{N} \mathrm{MLT}^{-2}$ \\
\hline$d$ & Particle diameter $\mu \mathrm{m} \quad \mathrm{L}$ \\
\hline$\kappa$ & Magnetic susceptibility $\quad-\quad-$ \\
\hline$B$ & Magnetic field strength $T \mathrm{IL}^{-1}$ \\
\hline$\rho_{p}$ & Particle density $\mathrm{kg} \mathrm{m}^{-3} \mathrm{ML}^{-3}$ \\
\hline$\rho$ & Fluid density $\mathrm{kg} \mathrm{m}^{-3} \mathrm{ML}^{-3}$ \\
\hline$g$ & Acceleration due to gravity $=9.81 \mathrm{~m} \mathrm{~s}^{-1} \mathrm{~m} \mathrm{~s}^{-2} \mathrm{LT}^{-2}$ \\
\hline$R e_{p}$ & Particle Reynolds number \\
\hline
\end{tabular}

\section{Acknowledgments}

The authors would like to thank EPSRC, and BP Oil for funding this work and Jan Campbell and George Blair of BP Oil for providing the test facilities.

\section{References}

[1] W.P. Hettinger (1992). Magnetic and chemical properties of magnetically separated fractions of equilibrium cracking catalyst laden with iron, nickel and vanadium and the development of the magnacat process and magnetic hooks for selectively removing old catalyst. Catalyst Today, 13, 155-189.

[2] S. Andersson and M. Trond (1997). Test of magnetically separated catalysts in an ARCO pilot unit. Applied Catalysts A, 159, 291-304.

[3] J. Svoboda (1987). Magnetic Methods of Minerals Treatment. Elsevier, Amsterdam.

[4] J.P.K. Seville, U. Tuzün and R. Clift (1997). Processing of Particulate Solids. Blackie Academic and Professional, London. 


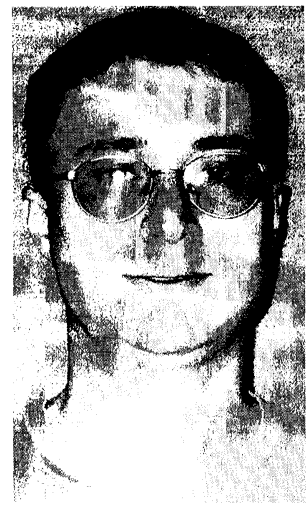

Mark Leaper has a degree in Chemical Engineering from Loughborough University, UK and an MSc in Bulk Solids Handling from Glasgow Caledonian University. He is finishing a $\mathrm{PhD}$ from the School of Chemical Engineering, University of Birmingham, UK, titled "Separation of Two Particle Systems" which includes a study of methods of preferentially removing deactivated catalyst from Fluidised Catalytic Cracking (FCC) systems to improve the yield of desired products. At present he is working as a research fellow at The Wolfson Centre for Bulk Solids Handling, University of Greenwich, London, as part of the Quality in Particulate Manufacturing (QPM) Programme, examining the caking, segregation and degradation of bulk solids. 